\title{
A Review on the Progress of Ecological Environment Research and Improvement of the Yellow River Basin
}

\author{
Yu Tianchen ${ }^{1, a^{*}}$ \\ ${ }^{1}$ Hohai University College of Hydrology and Water Resource, Gulou, Nanjing, Jiangsu, Chia
}

\begin{abstract}
Ecological protection and high-quality development in the Yellow River Basin is a major national strategy for regional economic growth and embodiment of green and coordinated policies. This paper expounds the research direction, implementation measures and existing achievements in the ecological theme for the Yellow River basin in China. It also introduces the methods to realize ecological optimization from the perspective of water resources, which is of certain significance for the further development of ecological protection and rational utilization of water resources in the basin.
\end{abstract}

\section{Introduction}

Considered the mother river of the Chinese nation, the Yellow River is the source, blood and soul of the sustainable development of the Chinese nation. It flows 5,464 kilometers and covers an area of more than 750,000 square kilometers. It runs from the headwaters of Qinghai to the mouth of Shandong. The Yellow River is China's important farming and animal husbandry production base. It is also very rich in natural, historical and cultural resources but its basin is fragile in the ecological matters.

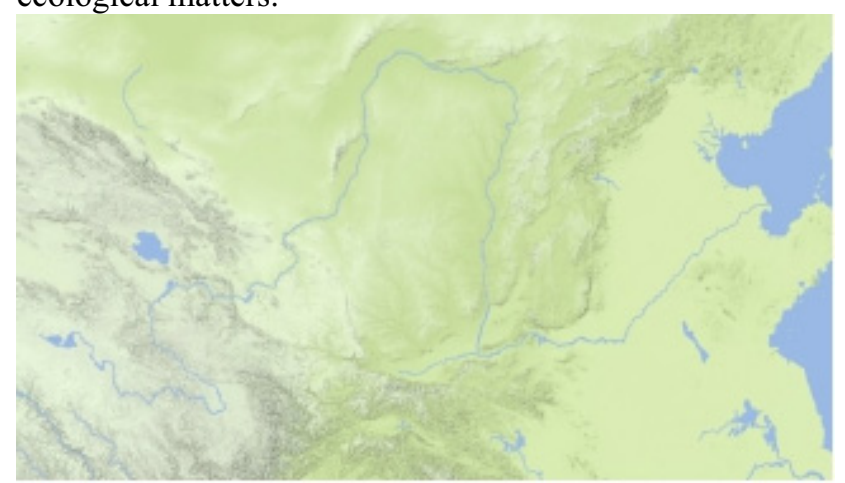

Figure1 Location map of the Yellow River Basin

The upstream section of the Yellow River flows from its source to the QingHai Inner Mongolia Hohhot togtoh county, through the Ningxia hui and Inner Mongolia autonomous region, Gansu, Sichuan and Qinghai Province. The upper section contain steep mountains, big gap and rich hydropower resources. The water flow is sandy and not uniform. The river then flows out of The Qingtongxia Gorge into the Plain of Ningxia and Hetao of Inner Mongolia. Canals crisscross around this area, thus being one of the earliest agricultural development zone in the upstream area. Overall the water is abundant, but there is an imbalance between water, sediment pollution, and control pressure.

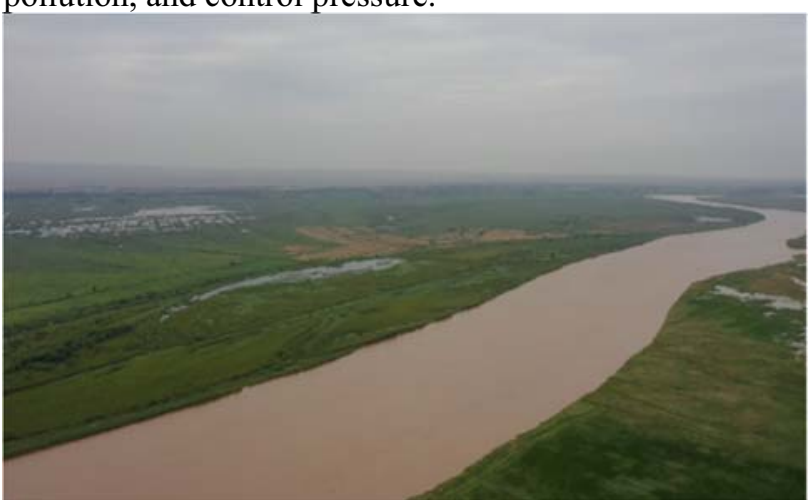

Figure2 The Yellow River upstream section in QingHai

In the midstream and upstream dividing line in the estuary of Inner Mongolia, priority is given to the mountain middle section through the Shaanxi, Henan and Shanxi Province, summer, autumn rain and peak flow. The sediment concentration is high, becoming the world's famous sandy river. There is an interaction of river channel deposition and erosion, and intersection of canyon and wide valley.

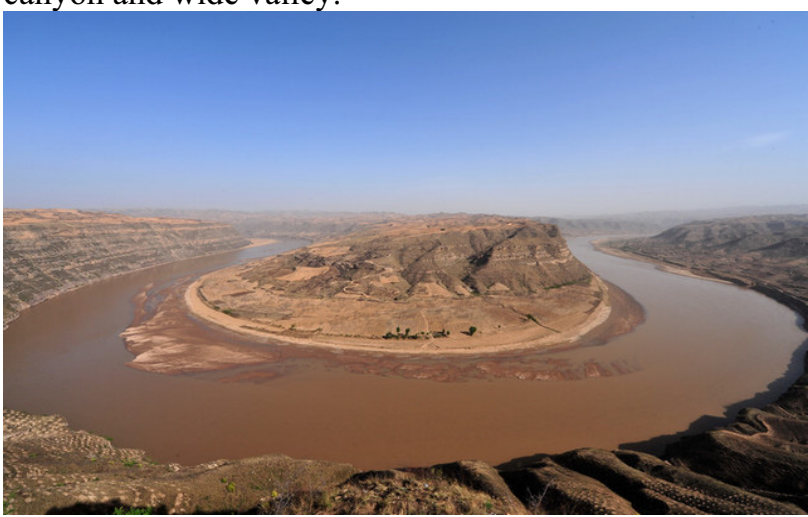

Figure3 The Yellow River midstream section in QingHai

\footnotetext{
* Corresponding author: ${ }^{a} 1946219468 @ q q . c o m$
} 
The water in the downstream section flows through Shandong and Henan, which is wide and shallow and has a small slope, gentle water flow, and serious silting. The river bed gradually rises, almost entirely relying on the river levee as a barrier. The beach surface of the river is generally about 25 meters higher than the surface of the two banks, and some are as high as 10 meters, making it a world-famous suspended river.

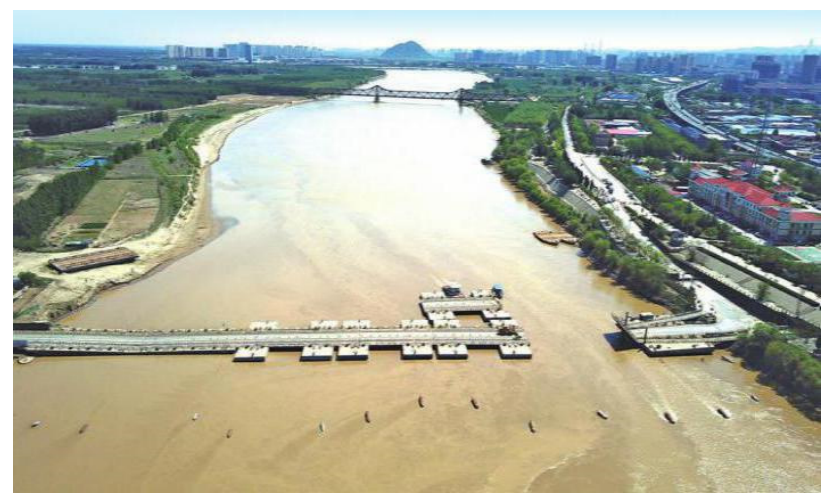

Figure4 The Yellow River downstream section in QingHai

\section{Research Status of Ecological Environment of the Yellow River Basin}

\subsection{Research on Ecological Protection of the Yellow River Basin}

There are three geographical features in the Yellow River basin: upper, middle and lower reaches. The location, natural ecology and resource carrying capacity determine the different functions of upper, middle and lower reaches. The realization of ecological restoration in the upsteam mainly focuses on headwaters conservation. This provides corresponding resource support and policy guarantee for water and sand regulation, pollution control and protection of ecosystem health in the basin, thus being an improvement of biodiversity.

At present, in view of the differences in location and endowment characteristics among different valleys of the basin, China has made an active exploration, transforming the "priority" of ecological protection into the "advantage" of high-quality development, thus, implementing regional division of labor and coordinated governance. In line with the harmonious coexistence between man and nature, we will strictly observe the requirements and the bottom line for ecological protection, environmental quality and resource utilization. We will build a green, low-carbon and circular development system by taking the characteristics of the resource endowment of the Yellow River Basin as the starting points.

In 1999, the Yellow River Water Conservancy Commission implemented a unified water volume regulation for the whole river, meaning a coordinated allocation of national water, unified upstream and downstream regulation, and complementary abundance and exhaustion study ${ }^{[1]}$. Since the implementation of the policy, the Yellow River has not been cut off for 21 consecutive years, and the water used for domestic consumption and industrial production in the basin and related areas has been improved and effectively guaranteed.

The current flows through the Loess Plateau and brings a mass of sediment into the river. The maximum annual sediment transport volume reaches 3.91 billion tons $^{[2]}$. A large amount of sediment will cause water quality problems and riverbed changes, which will have an impact on the ecology of the river basin and the lives of residents. Because the sediment in the basin is affected by changeable climate conditions, watershed environment, human activities and other aspects, and the source changes are complex and difficult to predict, therefore, scholars have some differences in their research on $i^{[3]}$. In recent years, with the enrichment of theoretical research, the rising of science and technology, rapid development of the Yellow River sediment research, many actions have been implemented such as the riverbed evolution and river regulation, water and sediment regulation technology, and effective management and utilization of silt sediment, thus easing the Yellow River water quality deterioration and riverbed elevation(shown in figure $5,6^{[4]}$ ). As a result, the quality of life of residents in the basin is improved, and the engineering efforts have made huge contributions to the development of sediment disciplines, being positive for society and environment ${ }^{[5]}$.

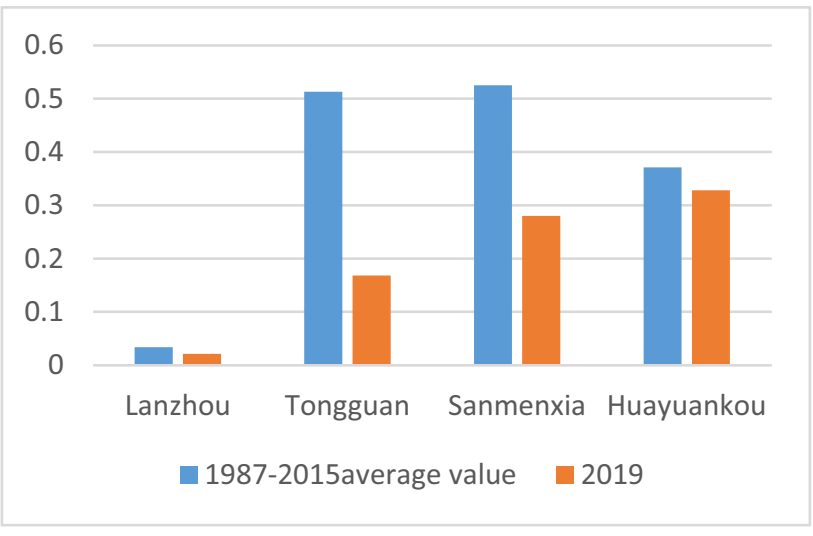

Figure5 Annual sediment transport at multiple stations in the Yellow River Basin (billion t)

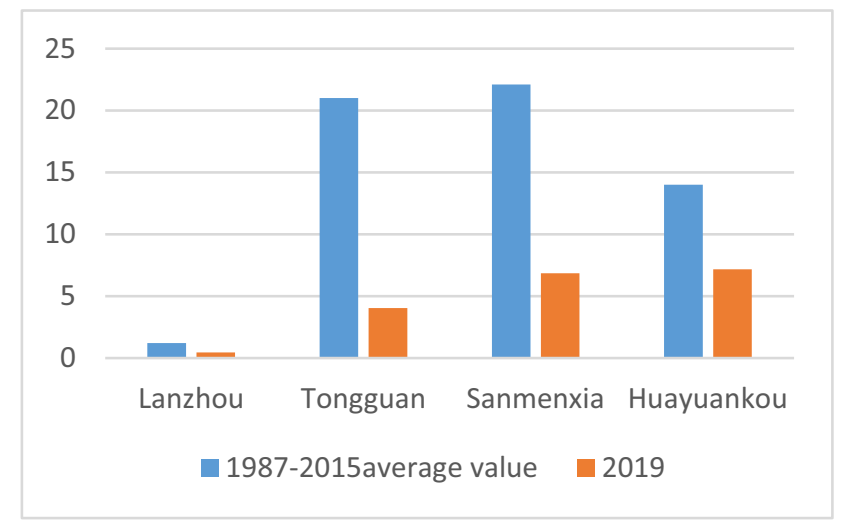

Figure6 Annual sediment concentration at multiple stations in the Yellow River Basin $\left(\mathrm{kg} / \mathrm{m}^{3}\right)$ 
Sediment also causes soil erosion, the most typical and serious ecological environmental problem. Its formation is mainly due to gully development, soft soil, less vegetation, concentrated rainfall, and large evaporation. It is often accompanied by problems such as weakened water conservation functions, river barrier, low level of ecological base flow protection in rivers and lakes, and decline of biodiversity. Aiming at the problem of soil and water loss in the Yellow River basin, China has actively carried out some major global and fundamental researches on the change and evolution trend of the relationship between water and sediment, such as the comprehensive improvement and control countermeasures of the "secondary suspended river" and the downstream tidal flats. According to the existing results, China has been implementing forest grassland construction, biological sand fixation, and returning farmland to water conservation measures. These measures will ensure the connectivity of rivers and lakes, protect the wetlands, and restore the biological habitats. By 2018, a water and soil erosion area of $218,000 \mathrm{~km}^{2}$ been harnessed, almost half of the total, consequently, the sediment content of the Yellow River has been improved. Tongguan hydrological Station shows that the annual average sediment transport decreases from 1.6 billion to 244 million, with a reduction of $85 \%{ }^{[6]}$, showing significant governance effect.

\subsection{Research on Water Resources Utilization in the Yellow River Basin}

The Yellow River basin covers a vast area. Water resources are not uniformly existed in the reach, resulting in the waste and pollution of water resources in the upstream water source. Meanwhile the water resources in the midsteam and downsteam are deficient ${ }^{[7]}$. The research on the utilization of water resources mainly focuses on pollution control and rational development.

There are rapid developments on industrialization, agriculture and urbanization along the basin, and discharge a large number of harmful substances into the river. Therefore, the Yellow River water quality decreases year by year, and the content of harmful substances exceeds the standard content ${ }^{[7]}$. The upstream pollution flows downward, laying a hidden danger for the water there. At present, the pollution in the basin has caused a lot of problems, such as crop reduction, poisoning and illness of surrounding residents, and caused huge losses to local residents' life, social economy and ecology. To take defensive measures, protection means such as water quality monitoring and water conservation have been implemented to realize the coordination from both sides of the river, three sections of the reaches and the overall planning from region to basin $^{[8]}$, so as to ensure the overall ecological security of the valley.

The Yellow River water supply area draws 55.59 billion cubic meters of water and consumes 45.54 billion cubic meters of water. In addition, there are serious waste and insufficient regulation capacity. The ecological water demand of the downsteam area reaches 25 billion cubic meters, and the social and economic water use of the basin reaches 30 billion cubic meters. There is a certain challenge between the ecological security and the local social development ${ }^{[9]}$. For this reason, China has carried out research on coordinated and planned water use to realize water efficient utilization on the premise of ensuring ecological civilization construction. By perfecting the Wackernagel ecological footprint model, the researchers established a suitable calculation method for the ecological footprint of water resources in China $^{[10-11]}$, which has been applied to the Yellow River, providing a strong support for the ecological protection of the Yellow River basin. With the popularization of social development, scientific and technological progress and environmental protection awareness, the coordination relationship between water resources utilization and economic development in the basin has been significantly improved. From 2004 to 2017, the water resources was sufficient, and the utilization efficiency was also improved ${ }^{[12]}$.

Water resources are closely related to the ecological environment. The overall planning of water resources utilization and ecological restoration is of great importance to the rational, efficient and clean utilization of the limited resources within the planned area, and is of far-reaching significance to the improvement of economic concentration, regional connectivity and policy coordination. Consequently, it will lead to high-quality economic and social development in China.

\section{Conclusions}

As the mother river of the Chinese nation, the ecological and environmental problems of the Yellow River have been widely concerned. Its protection and development have a vital impact on the improvement of the living standards of the people and the development of the national economy. At present, China's research on the Yellow River basin mainly relates to ecological protection, flood control safety, high water quality, advanced water culture environment construction and water resources management as to coordinate the relationship between water and sediment, and prevent pollution and exploitation. The implementation of the Yellow River resources conservancy and ecological protection has a great impact on the development of high-quality engineering practices, being positive for the people's livelihood. Judging from the current treatment results, the ecological restoration of the Yellow River basin is proceeding steadily, the water quality of some areas has been significantly improved, and the ecological environment construction has achieved outstanding results. The strategy for ecological protection and high-quality development of the Yellow River basin is gradually clarified and it can be predicted that it will achieve greater goals. This study can provide some basis for the direction selection, scheme design and effect prediction of the ecological protection and high-quality development of the Yellow River basin in the future. 


\section{References}

1. Yuguo, N., Caijun, Y. (2020) Practice of Ecological Civilization Construction in the Yellow River Basin. J. China Water Conservancy.

2. Shiyang, G., Guishu, X. (2020) Sources and Regional Distribution of Sediment in the Yellow River. J. People's Yellow River.

3. Enhui, J. (2020) Progress and Trend of Sediment Research in the Yellow River. J. Journal of Water Resources and Construction Engineering, 18: 1-9.

4. Yellow River Conservancy Commission of MWR, 2020. Yellow River Sediment Bulletin. http://www.yrcc.gov.cn/nishagonggao/2019/index.ht $\mathrm{ml} \# \mathrm{p}=1$.

5. Enhui, J., Yuanjian, W., Yuanfeng, Z., et al. (2016) New Progress in the Study of Sediment in the Yellow River [J]. People's Yellow River, 38: 24-37.

6. Chunhong, H., Xiaoming, Z., Yang, Z. (2020) Characteristics of Sediment Evolution in the Yellow River Over the Past Century and Causes of Recent Fluctuations. J. Progress in Water Science, 31.

7. Kai, L., Lei, D., Yanlong, Z., et al. (2017) Discussion on the Utilization and Protection of Water Resources in the Yellow River. J. Science and Technology Innovation Guide, 24: 118-122.

8. Min, Z. (2015) Shocking Pollution of the Yellow River. J. Ecological Economy.

9. Hua, D., Jian, Z. (2019) Yellow River Water Resources Management and Protection and Ecological Civilization Construction. J. Global Markets.

10. Zhongmin, X., Zhiqiang, Z., Guodong, C., et al. (2003) Ecological Footprint Calculation and Development Capacity Analysis in China in 1999. J. Journal of Applied Ecology, 14: 280-285.

11. Xiaoqiu, F., Cuiling, J., Xing, C., et al. (2005) Evaluation Model of Sustainable Development and Utilization of Water Resources: Research on Ecological Footprint of Water Resources. In: 2005 China Forum for Sustainable Development Organizing Committee. 2005 China Forum for Sustainable Development. Beijing. 588-593.

12. Rui, L., Yanxin, Z. (2020) Evaluation of Water Resources Utilization in the Yellow River Basin Based on Ecological Footprint of Water Resources. J. People's Yellow River, 42: 48-52. 